\title{
REPRESENTAÇÕES LITERÁRIAS NOS ESPAÇOS AMAZÔNICOS: LEITURAS DE MARGEM ${ }^{1}$
}

\author{
Olga Maria Castrillon-Mendes ${ }^{2}$
}

RESUMO: O presente artigo encerra uma proposta de reflexão sobre o processo de construção dialética de uma literatura que se estende por variados campos de representações sociais em que a história e a memória projetam discursos que se re-atualizam. Pesquisas têm demonstrado que, diferentemente das imagens estereotipadas construídas através dos tempos, o Brasil mais interior e por isso menos conhecido, possui uma vasta produção literária, muitas vezes de difícil acesso. Trata-se de um acervo valioso que, além de necessitar de tratamento especializado, requer estudos que o tornem aberto à diversidade de interpretações a fim de que, conhecendo-se o processo sócio-histórico de formação das identidades que compuseram o mosaico cultural amazônico, seja possível realizar uma re-visão da história cultural do continente.

PALAVRAS-CHAVE: Literaturas. Acervos Históricos. Amazônia. Pluralidade Cultural. "Regiões Culturais".

Neste artigo proponho socializar alguns pontos de um trabalho inicial sobre a constituição dos discursos contraditórios que construíram a ideia de Amazônia, principalmente, a Amazônia mato-grossense, colocando-os como mais um esforço no sentido de reconhecer e dar visibilidade à diversidade cultural brasileira. Esses discursos surgidos em meio a conflitos sociais envolvem um universo cultural variado que se relaciona a outras culturas do fragmentado universo latino-americano.

Pesquisas têm demonstrado que o Brasil mais interior e, por isso, menos conhecido pelo que é considerado, hoje, o centro, possui uma vasta produção literária e cultural, muitas vezes ainda de difícil acesso, justamente pelo descaso histórico e pela ausência de atitudes mais ousadas dos próprios

\footnotetext{
${ }^{1}$ Uma versão preliminar deste artigo, com o título "Narrativas em trânsito nos espaços amazônicos: história e representações literárias" foi apresentada na forma de comunicação em Simpósio Temática e publicada nos Anais do XXVII Simpósio Nacional de História, Associação Nacional de História, ANPUH, realizado em Natal, Rio Grande do Norte, no período de 22 a 26 de julho de 2013.

${ }^{2}$ Doutora em Teoria e História Literária, Professora da Universidade do Estado do Mato Grosso.
} 
agentes sociais dessas "regiões culturais". ${ }^{3}$ Trata-se de um acervo composto de cartas, diários de viagem e periódicos que, além de necessitar de tratamento especializado, requer estudos que o torne aberto à diversidade de interpretação, a fim de que, conhecendo o processo sócio-histórico de formação das identidades que compuseram o mosaico cultural amazônico mato-grossense, possam proporcionar a re-visão da história e da literatura produzida nas regiões brasileiras e em todo o continente latino-americano.

Para isso, é necessário entender que o espaço geográfico de localização dessas culturas faz parte de um complexo processo de formação histórico-colonial repleto de conquistas, explorações científicas, extrativismo, compondo o viés pelo qual poderão ser analisadas e melhor compreendidas as produções culturais ditas "de margem", no macrossistema em que se insere, ou seja, no macrossistema latino-americano.

Desta forma, minha análise propõe compreender a produção literária oriunda dos processos multiculturais em cujo interior se assenta grande parte da complexidade e multiplicidade de discursos que conformaram as relações de poder na América Latina. Assim, é possível reconhecer, a partir de Mato Grosso, o movimento de construção das identidades, das fronteiras diversas, das territorialidades como função da história, da literatura e de outras manifestações de linguagem na construção das nações e nacionalidades, temas que contribuem para o redimensionamento dos estudos atuais sobre os sentidos do local/regional e universal/geral, com base enfática nas noções de "literatura -mundo". "Nessa perspectiva, é possível se pensar no material de análise, instituindo o lócus da interlocução pelas vias do diverso.

No dizer de Pierre Bourdieu, se se pensar cada espaço de produção cultural como "campo", evita-se o reducionismo, a "projeção rebaixadora" de um espaço a outro (BOURDIEU, 1996, p. 226). Trata-se de examinar a estruturação dos campos e as posições assumidas pelos sujeitos históricos na hierarquia estabelecida entre eles e os efeitos causados pela dominação simbólica.

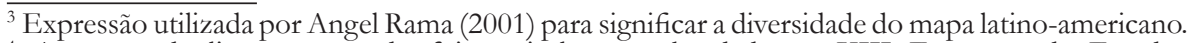
4 A noção de literatura-mundo foi verticalmente abordada no XIII Encontro de Estudos Comparados de Literaturas de Língua Portuguesa, de 16 a 18 de abril de 2013, na FFLCH/USP. Ressalte-se a abordagem da Prof ${ }^{a}$ Dr $^{a}$ Helena Carvalhão Buescu, da Universidade de Lisboa sobre a perspectiva da abrangência interdisciplinar das análises em detrimento dos paradigmas local/ universal. 
Assim, por exemplo, são conferidos à literatura e ao escritor, até meados do século XIX, os modelos de pensar e a forma de agir intelectualmente.

O texto literário se constituía em normas de conduta social, veiculando mensagens homogeneizadoras de cunho maniqueísta, identificadas com a hierarquia política de nações como a França e a Alemanha. A partir do século XX abrem-se novos espaços e posições culturais com base na compreensão das variadas visões de mundo, próprias a cada grupo social a que os escritores pertenciam. Assim especificados, cada campo social congregava os seus portavozes. Nas primeiras décadas do XX, os estudos críticos de Ezra Pound ${ }^{5}$ sinalizavam para a função do artista como “antenas" ligadas aos efeitos da criação, no caso, o poema (e não o poeta). Significa que o conhecimento passa pelo exame cuidadoso dos fatos, por isso, o intelectual começa a se colocar entre as palavras, na "dança do intelecto [...] que trabalha no domínio específico das manifestações verbais" (POUND, 1990, p. 11). A decantada mensagem do texto dá lugar para o labor da palavra que se torna arma de luta que visa a transformação do leitor.

Ao analisar, portanto, uma forma literária, procura-se não mais a linearidade passado/presente, mas a inter-relação que a situa no que se pode chamar, com Benjamin Abdala Junior, movimento dialético da espiral (ABDALA JÚNIOR, 2007, p. 13). Neste sentido, a figura de linguagem evidencia não a circularidade positivista, a repetição de fórmulas estabelecidas, mas a perspectiva da dialética da forma literária na sua historicidade. Ou como diz ainda o crítico, a estrutura artística nos contraditórios e complexos processos históricos controlados pelos diversos e contraditórios agentes do poder. Essa dinâmica é um movimento incessante, e sempre crescente, que retoma, interfere e projeta a diversidade das formas de modo a transformá-la em objeto artístico num campo relativamente autônomo. As marcas dele advindas são possíveis de administrarem, por um lado, as diferenças e, por outro, a preservação da hegemonia.

Nesse sentido, articulam-se os textos produzidos à historicidade (nem sempre demarcadora) da produção artística brasileira e à práxis do

\footnotetext{
${ }^{5}$ Refiro-me, aqui, ao pragmático $A B C$ da literatura. São Paulo: Cultrix, 1990. Augusto de Campos antecipa no prefácio que é um manual para ser lido com prazer e proveito por todos os que esmiúçam cuidadosamente os fatos, no caso, os fatos da língua.
} 
intelectual. Busco, portanto, compreender as dinâmicas desse "poder simbólico" no conjunto da produção literária de Mato Grosso, apoiando minhas reflexões nos estudos elaborados por Pierre Bourdieu (1996 e 2010). Interessa-me, sobremaneira, aliar o conceito de poder simbólico ao de campo literário e o consequente lócus de enunciação do intelectual de margem.

As relações de poder permitem que uma cultura se sobreponha a outras, comprimindo-as de maneira a sufocar experiências sócio-históricas e intervenções singulares que surjam de outros locais fora do eixo hegemônico e, portanto, irradiadores de padrões de comportamento social. Por esse viés, as ideias de Lucien Goldmann (1990) sobre o método estruturalista genético na história da literatura, têm contribuído para se repensar o processo de interação entre o autor e o grupo social a que pertence. Longe de querer discutir aqui a questão da autoria, interessa-nos a postura do escritor perante o grupo que representa e que o transforma no elo entre a criação e o sujeito leitor inserido num determinado grupo social. Desta forma, a obra literária não é mais considerada pedagogia ou um reflexo da realidade, como no realismo/naturalismo do século XIX, mas está na tensão literatura/sociedade, dicotomia já estudada por Luckács e retomada por Goldmann que introduz o conceito de historicização da forma, cujo sujeito social atua de diferentes formas, tanto usando seus canais próprios de observação, quanto reflexão e interação com o interior da sociedade que se expressa pelo termo trans-individual. Ou seja, a busca das homologias, o estudo das estruturas significativas (compreensão mais globalizante) que confere unidade à obra literária, tornando inteligível a sua gênese. Assim, cada obra é fruto inseparável, não apenas da psicologia do autor, mas do fator social presente na sua estrutura.

No Brasil, Antonio Candido empenha-se na compreensão da síntese desse universo sócio-cultural dado pelas "tendências universalistas e particularistas" desde as primeiras manifestações literárias (CANDIDO, 1997, p. 23). O "sistema simbólico" articulado autor/obra/público de que trata tem validade histórica na construção nacional, ou como diz, lembrando estudo de Julien Benda, ${ }^{6}$ uma história dos brasileiros no seu desejo de ter uma literatura.

\footnotetext{
${ }^{6}$ Julien Benda (1867-1956) teorizou a independência política e neutralidade partidária dos intelectuais. Ficou conhecido pela obra "La trahison des clercs", traduzido como "A traição dos intelectuais". Para ele, trai os valores intelectuais o indivíduo que busca interesses particulares em
} 


\section{Acessando arquivos}

Desde o século XVIII a fronteira oeste brasileira foi foco de tensões, surgindo imagens que marcaram a já tão gasta (e ultrapassada) ideia de sertão. Naquele momento, várias foram as investidas de reconhecimento do interior brasileiro de forma a tornar conhecido o que era desconhecido dos próprios brasileiros. Podemos dizer que o projeto iluminista que concebeu a idéia de Mato Grosso teve sua gênese no espírito renovador de Pombal, cuja ação, no dizer de Antonio Candido, foi decisiva e benéfica para o Brasil, favorecendo atitudes mentais evoluídas, que incrementariam o desejo de saber e a adoção de novos pontos de vista na literatura e na ciência (CANDIDO, 1997, p. 63). Ou seja, o pensamento letrado marcando a hegemonia cultural.

Nesse período muitas são as produções narrativas de viajantes e escritores que constituíram o que Candido chamou de "manifestações literárias". Formas estereotipadas que ganharam amplo poder de circulação, cujos gestos e sonhos foram inseridos num imaginário "mais amplo, mestiço e oriundo de nossa formação mestiça", nos estudos de Benjamin Abdala Júnior (2002, p. 11).

Muitos dos investimentos na ocupação de terras latino-americanas foram transformados em produto das experiências da viagem. Aliados a outros escritos, elaborados por diferentes observadores sociais, formam a diversidade étnica e cultural para a nossa constituição de povo, de raça e de processos ideológicos. Tais práticas culturais exerceram importante papel social na construção dos sujeitos amazônicos, prenunciando como o século XIX recortou o mundo e como as imagens escritas e desenhadas, por olhares outros, se mesclaram para construir novos processos de significação.

A memória construída por esses movimentos produz um sentimento de identidade e de pertencimento de forte marca estrangeira, gerando o desconforto do lugar de não origem, como tratado por Julia Kristeva. Tal sentimento possibilita a re-criação de paradigmas para os sistemas de pensamento, fornecendo ao escritor a conquista e a tradução da terra, pelo olhar (KRISTEVA,

detrimento dos universais (clercs é o termo utilizado para referenciar os homens letrados de sua época). 
1994). Dessa forma, cria o espaço de intersecção no processo de construção/ superposição das imagens, não como ponto fixo, mas construção móvel que não diluem a perspectiva de outros olhares, ao contrário, a configuração deles fornece a abrangência cósmica de estar no mundo e não fora (ou à margem) dele.

Nesse caminho, concebemos identidade como uma manifestação individual e coletiva que unifica e faz com que os indivíduos se reconheçam ao estabelecerem suas diferenças em relação a outros indivíduos com base em atributos sociais e culturais comuns. Falando com Michael Pollak é a relação entre memória e identidade social como um fenômeno que se produz em referência aos outros, em referência aos critérios de aceitabilidade, de admissibilidade, de credibilidade, e que se faz por meio da negociação direta com os outros (POLLAK, 1992, p. 204).

Nessas relações multiculturais, as interpretações buscam assinalar a lógica da colonização re-visitada. As consequências de tais investidas resistem no ideário de modernidade e são enfrentadas nas perspectivas teóricas e críticas para se compreender as políticas e culturas plurais dos continentes, como é o caso da América Latina. Pode-se dizer que as literaturas e culturas produzidas nos variados espaços de significação estão imbricadas no presente, constituindo a multiplicidade dos territórios de vivência humana que permitem compreender o nosso comunitarismo cultural, na perspectiva analisada por Abdala Júnior, como de interesse científico e artístico de modo a afirmar o nosso rosto diferenciado. "Um rosto híbrido e complexo, tenso e solidário capaz de se afastar das mesmices da estandardização dos produtos culturais” (ABDALA JUNIOR, 2002).

Adotamos, nessa linha, a dinâmica da dialética social que privilegia a operacionalização de conceitos como multiculturalismo, transculturalismo, hibridismo e representação na construção de traços identitários que reverberam os sentidos de territorialidade dos sujeitos, cuja base analítica nos fornece elementos para pensar a comunicação artística identificada pelas raízes que movem a história na busca de um conceito para Mato Grosso a partir da sua produção literária. Não a tradição, nem tampouco o folclorismo reducionista, mas a sua tradução, a consciência da atividade produtiva que permite novas formas de pensar/compreender os sujeitos no espaço das produções culturais brasileiras em suas interrelações culturais. 
Esse percurso de produção somente é possível a partir da formação de um banco de dados significativos para a compreensão das fronteiras locais, pois os arquivos se dão à diversidade dos gestos de leitura, conduzindo a variadas interpretações. Isso se liga à formulações anteriores sobre a produção crítico-literária de/em Mato Grosso que venho explorando a partir de material bibliográfico e de publicação em periódicos depositado nos acervos públicos e particulares. Pela via da diversidade de fontes está sendo possível a re-visão do acervo e, consequentemente, dos conceitos estabelecidos.

\section{Discursos em conflito}

No momento de calorosas discussões sobre velhas e novas identidades, dois pontos se estabelecem como pauta nesta proposição. $\mathrm{O}$ primeiro é não deixar de traduzir a tradição como foi dito; o outro é intensificar o processo de autoconhecimento dos espaços de produção cultural através da invenção do arquivo literário na reconstituição da "memória de uma cultura", como propõe Ana Pizarro (2005) num contexto e numa visão das regiões sobre si mesma e em relação a outros espaços e diversidade.

Essa configuração heteronímica pode ser explicada na perspectiva do deslocamento do sujeito contemporâneo perante as transformações estruturais advindas da "globalização" vistos, principalmente, por Stuart Hall (2006) e no quadro analítico das dificuldades da sociedade portuguesa no processo de transição paradigmática, posto pelo sociólogo Boaventura Santos (2003). Ambos os estudiosos da chamada pós-modernidade atingem modos de conhecer que se ligam à transformação dos modos de organização das sociedades.

As diversidades constituem, portanto, motivo de revisão da sociedade brasileira em tal transição. Então, o lugar de Mato Grosso e o conceito que tem adquirido no contexto sócio-cultural-brasileiro-amazônico e na América Latina é, inicialmente, no período de ocupação (os viajantes cronistas, naturalistas e missionários), o lugar da fantasia, portanto, o estigma da imaginação/invenção. Como fala Sérgio Buarque de Holanda, o "paraíso", cuja visão encantou os viajantes (HOLANDA, 2000). Pela produção cultural é possível rever 
as manifestações literárias que compõem o acervo bibliográfico de modo a construir, num trabalho coletivo, uma historiografia literária que constitua base para a compreensão dos sistemas literários das sociedades analisadas. Trata-se, então, de uma revisão que não se pauta em manter as relações de poder simbolicamente estabelecidas, mas de observar a relação entre o que está posto historicamente e o material estético a ser observado. O problema central é não perder de vista as singularidades específicas de cada material analisado e a permanência (ou não) da forma.

Não mais os mitos relativos à barbárie, mas as diferentes dimensões culturais que passa pela renovação do olhar, levando em conta concepções de região em sua diversidade social e cultural, sem deixar de levar em conta os problemas da modernização. No caso estudado, "as Amazônias" como uma unidade cultural complexa que se liga, pelas singularidades, a outras regiões do continente, levando em conta o plano do simbólico. Nesse aspecto, é possível ressaltar algumas produções como Cobra Norato, de Raul Bopp, com a escrita sobre as culturas da selva tropical e personagens "encantadas" que se ligam a outras representações amazônicas como Matrinchã do Teles Pires, de Luis Renato Souza, Trilogia cuiabana, de Silva Freire, Madona dos páramos, de Ricardo Guilherme Dicke, os contundentes folhetins de Márcio Souza Galvez, imperador do Acre e Mad Maria, todos voltados para recuperação de uma perspectiva local que não se fecha, mas une combinação das formas da tradição com a sofisticação dos sistemas modernos de comunicação. Não mais culturas consideradas "bárbaras" ou "primitivas", mas o estrato interior visto por Angel Rama, como o mais profundo da literatura latino-americana e que coloca por terra as velhas pretensões etnocentrista (RAMA, 2001, p. 303).

É muito difícil acercar-se de conceito tão fluido (e contraditório) quanto o de América Latina, principalmente quando se debruça sobre a relação entre a produção cultural e a função do intelectual. Na vasta produção de Rama é possível verificar três grandes sistemas literários latino-americanos já constituídos: o mexicano, o brasileiro e o de Buenos Aires, o que pode parecer reducionista demais para significar o mapa do continente. No entanto, essa constatação permite pensar as formações de margem dentro das diferenças existentes 
na língua e na tradição. E o que se vê é uma forte tendência ao pensamento utópico frente ao processo de modernização construído coletivamente sem que, para isso, se perca a tradição. Como dissemos, ela passa a ser traduzida, como acontece na narrativa de Ricardo Guilherme Dicke que evoca o tempo mítico e os traços de poder pela posse de terras em Mato Grosso, mas que pode ser representativo de qualquer conflito dessa natureza em qualquer lugar do planeta. É a partir dessa constatação que o grupo passa a dominar sua própria história e a contá-la à sua maneira, ou seja, há um passado comum evocado que constrói a consciência da história das perdas e dos silenciamentos vista por Rama como um "fazer de fronteira" em que o continente, assim como a literatura é "território da utopia” (RAMA, 2001, pp. 15-27).

Há, nessa abrangência de discursos, um elo com o político e com as relações de poder, que traça limite, demarca estereótipos e contribui para a compreensão da ideia de Brasil no contexto mais amplo, nas interfaces da busca do seu sentido enquanto nação expressa através da ciência e da literatura nativas, e o despertar para a fascinação pela paisagem natural. Provoca, desta forma, a epopéia fascinante da construção de uma memória americana pelas experiências transformadas em textos que constroem imagens plurais da América, compreensíveis nos/pelos espaços descobertos, nomeados, estabelecidos pelo maravilhoso-exótico que avizinham a história do fantástico e a produção do imaginário de forte ascendência européia. Portanto, uma historicidade marcada e reconhecidamente modelada por práticas alienantes, embora nos encontremos hoje num outro momento da discussão e, talvez, mais cristalizado pelas abalizadas discussões acadêmicas advindas, principalmente, dos centros do poder intelectual.

Nessa perspectiva e buscando os aportes desta discussão, os conceitos confluem para uma produção literária brasileira de/em de Mato Grosso, nas interfaces que carregam consigo as questões mais prementes entre regionalismos e identidades culturais, colocando em xeque a discussão de "margem" no processo de constituição da cultura brasileira. Delas surgem noções de raça, de povo, de paisagem, de espaços de significação na sobreposição, deslocamentos e entrelugares da diferença em que foram e são negociadas as representa- 
ções de poder - questões corroboradas pela linguagem que, performativamente, cria condições de cristalização dos discursos. Então, não é simplesmente rediscutir a tradição, mas reencená-la em outras temporalidades culturais.

Portanto, recuperando a tese de Ana Pizarro para o nosso foco discursivo, e forçando o plural, as Amazônias são "construções discursivas" (PIZARRO, 2005, p. 61). Chega-se a ela(s) pelo peso dos discursos míticos relativos à barbárie, impedindo uma abrangência de tipo cultural em que se integram diferentes dimensões sobre o espaço simbólico. Estamos, portanto, criando sistemas literários dentro de um macrossistema latino-americano.

Afetados por essa globalização somos todos mobilizados a mudar de postura. Fazemos parte de uma dinâmica plural de construção de identidades que, ao longo do processo de formação do povo, caracterizou o “jeito de ser” brasileiro já desenvolvido na obra Macunaíma, de 1928, personagem-síntese do conhecido escritor brasileiro Mário de Andrade. Desde então, imprime-se na literatura uma busca de sentidos circulantes em que a relação com o outro está presente no processo de colonização, mas que começou a fazer sentido no amálgama sócio-cultural que se estabeleceu a partir da junção de variados elementos provenientes do processo histórico vivenciado pelo século XX. Hoje, a diversidade que constitui a cultura imprimiu sentidos que representam uma "comunidade simbólica" pela qual se significa, como fala Stuart Hall (2006, p. 48). Ou seja, participamos de uma "tradição", uma "continuidade literária", cuja imagem Antonio Candido referencia como a "transmissão da tocha entre corredores, algo entre os homens, o conjunto de elementos transmitidos sem os quais, não há literatura como fenômeno de civilização" (CANDIDO, 1997, p. 24). Dessa forma, o híbrido cultural transmitido é seguidamente reinventado nas práticas e valores, sucumbindo com a ideia do anacronismo de povo puro e original ou literatura "nossa". Então, não se trata apenas do diálogo entre culturas interiores e exteriores, mas universos de tensões e contradições, vistos em ilhas de comunitarismos como expressas nas pesquisas de Abdala Júnior.

Ao trabalhar com a produção literária nos países de língua portuguesa, enfocando o processo discursivo engajado de uma literatura dialética que não se fecha, mas está “em processo", Abdala Júnior abarca os 
múltiplos campos dos referentes sociológicos e históricos, projetando um amplo debate de representações míticas e utópicas que se atualizam no/pelo devir da escrita comprometida com a perspectiva coletiva nacional. Nesse aspecto, é que se torna possível a tradução da tradição, como fazem os escritores que se afastam do seu lugar de origem, mas sem perder completamente suas identidades. Elas têm culturas híbridas, estão traduzidas. $\mathrm{O}$ aparente retorno, como frisa o crítico, implica na "reconfiguração da forma" que se dá através do papel consciente dos atores sociais, impedindo que ela se petrifique. "Não se trata, pois, de visualizar, na volta da estrutura, o modelo cíclico ou a sucessividade retilinear da representação do tempo, mas de situá-la na dinâmica do movimento dialético da espiral, que retorna, interfere e projeta essa forma" (ABDALA JUNIOR, 2007, p. 13).

No foco destas reflexões, o forte apelo à sociedade matogrossense não irá superar as identificações em curso e a mobilidade dos conceitos, pelo contrário, fará jus a um processo de releitura do arquivo, atentando para as relações de poder que instalam enunciados dominantes na estrutura social.

Portanto, ao colocar em cena o espaço cultural do Mato Grosso, evocamos uma operação constituída historicamente pela escrita, ou seja, pela produção literária dos intelectuais que tornaram possível, cada um ao seu modo, ou ao modo do grupo que representam, a reconstrução de uma "realidade" social. Como Pierre Bourdieu ao refletir sobre as regras da arte em um mundo submetido às próprias leis, tenho proposto não a celebração dos clássicos, nem o culto dos ancestrais, mas o espaço da liberdade fora do santuário da história e da fetichização do que passamos a considerar "coisa nossa". Por ser tão próximo a nós, teimamos, muitas vezes em não reconhecer (ou perceber) as regras.

Todo percurso aqui analisado nos leva à compreensão dos jogos simbólicos engendrados no campo intelectual num esforço de salientar preconceitos sobre a noção de arte ou de texto literário. Mas ao adentrar nos princípios da existência da arte como componente histórico e, se possível, ainda com Bourdieu, "transhistórico", tratando a obra como um "signo intencional habitado e regulado por alguma coisa da qual ela também é sintoma" (BOURDIEU, 1996, p. 156). 


\section{Algumas considerações finais}

A ideia de re-conhecer a produção literária local pode, portanto, contribuir para a re-visão da própria historiografia literária brasileira, incluindo escritores, obras e conceitos não reconhecidos pela crítica, fato resultante da escassez de trabalhos na área. O estudo do conjunto da produção de cada escritor local fará parte do complexo que implica uma forma de autodescoberta e de descoberta do outro pelos quais se compreenderá o jogo das relações de poder nas sociedades. Um jogo em que dois eixos se tornam visíveis: as representações literárias e o papel da memória e das relações políticas na constituição de uma cultura (supra)nacional. No primeiro eixo encontram-se os escritores brasileiros que produzem em Mato Grosso. No outro são levados em consideração os elementos estéticos que fazem da memória e da relação de poder, ingredientes básicos de permanência (ou não) de uma cultura supranacional, numa interlocução de amplitude da experiência de pensar estes saberes, materializados em discurso que se aproximam e se distanciam pelo respectivo caráter poético-ficcional. Não a ideia geral que tem confundido estudo pormenorizado, mas a perspectiva de acessar uma singular parcela desse imenso espaço cultural.

Sem perder de vista essa ideia norteadora, que pressupõe a existência de uma produção literária ligada ao conjunto das manifestações nacionais, pensar as obras dos escritores de margem fez emergir elementos da diversidade regional, os aspectos literários e extra-literários, colocando-os em sintonia (ou confronto) com o tempo e a história. Não um discurso hegemônico sobre o mesmo, mas o diferente e em relação ao outro, a outras comunidades. E nada mais original do que pensar esse Brasil, que se queria independente das influências externas, a partir de uma vivência amalgamada no espaço interior da imensa geografia brasileira, cuja história é exemplar importante para se pensar o movimento das conquistas, formador de povoamento, vilas e fortificações que se presentificam, contemporaneamente, no processo de ocupação dos espaços, no norte do estado. ${ }^{7}$

Geograficamente, a região "estranha", "distante", “desconhecida", repleta de "fatos lendários", que povoaram o imaginário de muitos

\footnotetext{
${ }^{7}$ Cf. Regina Beatriz Guimarães Neto (2002), sobre as frentes sulistas de colonização contemporâneas, na Amazônia, para o norte de Mato Grosso, uma experiência que vai "da miséria à invenção do paraíso" em movimentos para lugares distantes que guardam dimensões semelhantes aos de ontem.
} 
viajantes e estudiosos, foi significativamente, foco e palco de discussões das fronteiras definitivas do Brasil. Um caso de fronteiras do imaginário, que acompanha o movimento da viagem e liga-se ao sentido do político e das relações de poder que traçaram os limites da soberania portuguesa, pelos balizamentos dos rios Guaporé e Paraguai, dois ícones da paisagem fronteiriça. O rio Paraguai, pelo ciclo das águas que formam a bacia do pantanal sul-matogrossense, local das mais pungentes experiências pessoais, que foram responsáveis por grande parte do caráter da escrita de escritores do Romantismo que viajaram pelo interior brasileiro, a exemplo de Alfredo d'Escragnolle Taunay, o Visconde de Taunay.

Dessa forma, ao reencenar o passado memorialístico, a tradição é reinventada. Não há, portanto, uma identidade original, mas embate de identidades de fronteiras fixas e/ou móveis, estabelecendo situações de reconstrução e intervenções nas condições políticas do presente.

Assim, pensa-se Mato Grosso, como o resto do Brasil, a partir da mediação do "outro", disseminando-se idéias estigmatizadas alinhadas, principalmente, desde os debates sobre a inferioridade do Novo Mundo postos pelos estudos de Antonello Gerbi sobre o continente americano e seus habitantes (GERBI, 1996).

Se o espaço de que estamos tratando fez parte de um complexo muito mais abrangente, como se estaria, aqui, pensando a "margem"? Em relação a que(m)? Pois não se pode com isso, cair na redundância de se estar criando outro centro e outras margens.

Este texto pode funcionar como mais um esforço da vontade de vencer obstáculos que nos impedem de vislumbrar perspectivas de participar de uma revolução cultural que pode ter início aqui e continuar em outros setores da vida social, sucessivamente, como uma grande avalanche de vontades em busca de um ideal consciente. Ou, na tese de Boaventura Santos, reinventar o futuro como única saída para a exploração de novas possibilidades e vontades humanas, um deslocamento que permita a "heterotopia", do centro para a margem.

Essa é a nossa proposta no encaminhamento destas embrionárias discussões, esperando que o auto-conhecimento converta nossas práticas sociais em potencialidades universalizantes. 
Olga Maria Castrillon-Mendes

\section{NOTES ON LITERARY REPRESENTATIONS IN THE AMAZONIC SPACES}

ABSTRACT: The present work concludes a reflection on the process of dialectic construction of a literature that encompasses various fields of social representations, on which history and memory project self-renovating discourses. Research has demonstrated that, despite the stereotyped images constructed throughout time, the internal and therefore less known part of Brazil possesses a vast literary tradition, which is often hard to access. That is a precious corpus of works which, far from requiring a special treatment, needs to be explored in order to allow it to be opened to the diversity of interpretations, in a way to facilitate the revision of the cultural history of the continent by revealing the socio-historical process of formation of the identities that compose the cultural mosaic of the Amazon.

KEYWORDS: Literatures. Historical Archives. Amazon. Cultural Diversity. "Cultural Regions".

\section{Referências}

ABDALA JUNIOR, B. Literatura história e política: literaturas de língua portuguesa no século XX. SP: Ateliê Editorial, 2007.

ABDALA JUNIOR, B. Fronteiras múltiplas, identidades plurais: um ensaio sobre mestiçagem e hibridismo cultural. São Paulo: Editora SENAC, 2002.

BOURDIEU, P. O poder simbólico. Trad. Fernando Tomaz. 13 ed. Rio de Janeiro; Bertrand Brasil, 2010.

BOURDIEU, P. As regras da arte: gênese e estrutura do campo literário. Tradução: Maria Lúcia Machado. São Paulo: Companhia das Letras, 1996.

CANDIDO, A. Formação da literatura brasileira: momentos decisivos. 2 volumes. São Paulo/Itatiaia, 1997.

GERBI, A. O novo mundo: história de uma polêmica (1750-1900). Trad. Bernardo Joffily. São Paulo: Companhia das Letras, 1996.

GOLDMANN, L. Sociologia do romance. 3 ed.São Paulo: Paz e Terra, 1990.

HALL, S. A identidade cultural na pós-modernidade. Trad. Tomaz Tadeu da Silva e Guacira Lopes Louro. 11 ed. Rio de Janeiro: DP\&A, 2006.

HOLANDA, S. B. Visão do Paraíso: os motivos edênicos no descobrimento e colonização do Brasil. São Paulo: Brasiliense/Publifolha, 2000. 
KRISTEVA, J. Estrangeiros para nós mesmos. Trad. Maria Carlota Carvalho Gomes. Rio de Janeiro: Rocco, 1994.

NETO, R. B. G. A lenda do ouro verde: política de colonização no Brasil contemporâneo. Cuiabá: UNICEN, 2002.

PIZARRO, A. Imaginário y discurso: La Amazonía. Revista de crítica literária Latinoamericana. Año XXXI, No 61. Lima-Hanover, 1er. Semestre de 2005, pp. 59-74.

POLLAK, M. Memória e identidade social. Rio de Janeiro. Estudos históricos, vol. 5, n. 10, 1992, p. 200-12.

RAMA, A. Regiões, Culturas e Literaturas. In: AGUIAR, F. \& VASCONCELOS, S. (Orgs.). Angel Rama: literatura e cultura na América Latina. São Paulo: Edusp, 2001.

SANTOS, B. S. Pela mão de Alice: o social e o político na pós-modernidade. 9 ed. São Paulo: Cortez, 2003.

Data de recebimento: $16 / 07 / 2014$

Data de aceite: 27/08/2014 